\title{
Mutual Solubilities of Water and Hydrophobic Ionic Liquids
}

\author{
Mara G. Freire, ${ }^{\ddagger}$ Catarina M. S. S. Neves, ${ }^{\S}$ Pedro J. Carvalho ${ }^{\ddagger}$ Ramesh L. Gardas, \\ Ana M. Fernandes, ${ }^{\dagger}$ Isabel M. Marrucho, ${ }^{\ddagger}$ Luís M. N. B. F. Santos,,${ }^{\prime \prime}$ and \\ João A. P. Coutinho*,* \\ CICECO, Departamento de Química, Universidade de Aveiro, 3810-193 Aveiro, Portugal, Departamento de \\ Química, Universidade de Aveiro, 3810-193 Aveiro, Portugal, QOPNA, Departamento de Química, \\ Universidade de Aveiro, 3810-193 Aveiro, Portugal, and CIQ, Departamento de Química, Faculdade de \\ Ciências da Universidade do Porto, R. Campo Alegre 687, 4169-007, Porto, Portugal
}

Received: August 5, 2007; In Final Form: September 7, 2007

\begin{abstract}
The ionic nature of ionic liquids (ILs) results in a unique combination of intrinsic properties that produces increasing interest in the research of these fluids as environmentally friendly "neoteric" solvents. One of the main research fields is their exploitation as solvents for liquid-liquid extractions, but although ILs cannot vaporize leading to air pollution, they present non-negligible miscibility with water that may be the cause of some environmental aquatic risks. It is thus important to know the mutual solubilities between ILs and water before their industrial applications. In this work, the mutual solubilities of hydrophobic yet hygroscopic imidazolium-, pyridinium-, pyrrolidinium-, and piperidinium-based ILs in combination with the anions bis(trifluoromethylsulfonyl)imide, hexafluorophosphate, and tricyanomethane with water were measured between 288.15 and $318.15 \mathrm{~K}$. The effect of the ILs structural combinations, as well as the influence of several factors, namely cation side alkyl chain length, the number of cation substitutions, the cation family, and the anion identity in these mutual solubilities are analyzed and discussed. The hydrophobicity of the anions increases in the order $\left[\mathrm{C}(\mathrm{CN})_{3}\right]<\left[\mathrm{PF}_{6}\right]<\left[\mathrm{Tf}_{2} \mathrm{~N}\right]$ while the hydrophobicity of the cations increases from $\left[\mathrm{C}_{n}\right.$ mim $]<$ $\left[\mathrm{C}_{n} \mathrm{mpy}\right] \leq\left[\mathrm{C}_{n} \mathrm{mpyr}\right]<\left[\mathrm{C}_{n} \mathrm{mpip}\right]$ and with the alkyl chain length increase. From experimental measurements of the temperature dependence of ionic liquid solubilities in water, the thermodynamic molar functions of solution, such as Gibbs energy, enthalpy, and entropy at infinite dilution were determined, showing that the solubility of these ILs in water is entropically driven and that the anion solvation at the IL-rich phase controls their solubilities in water. The COSMO-RS, a predictive method based on unimolecular quantum chemistry calculations, was also evaluated for the description of the water-IL binary systems studied, where it showed to be capable of providing an acceptable qualitative agreement with the experimental data.
\end{abstract}

\section{Introduction}

In the past decade, ionic liquids (ILs) have received increasing attention as an emerging class of "neoteric" nonaqueous solvents. ${ }^{1}$ ILs belong to the molten salts group and are usually formed by large organic cations and smaller organic or inorganic anions, allowing them to remain liquid at or near room temperature. One of the most interesting characteristics of ILs is their high solvating capacity for both polar and nonpolar compounds, which, in combination with their negligible vapor pressures, nonflammability, wide liquid temperature range, wide electrochemical window, and high thermal stability defines their enormous potential as environmentally friendly solvents. On top of that, the possibility of finely tuning their intrinsic thermophysical properties ${ }^{2,3}$ opens a wide range on their application in the chemical industry. ${ }^{4}$ In particular, the use of ILs with lower mutual solubilities with water as biphasic extraction media for the removal of organics from water is an active area of research. ${ }^{5-7}$ Their important role in the recovery of acetone,

* Corresponding author. Tel: +351-234-370200. Fax: +351-234370084. E-mail address: jcoutinho@dq.ua.pt.

QOPNA, Departamento de Química, Universidade de Aveiro.

$\doteqdot$ CICECO, Departamento de Química, Universidade de Aveiro.

$\S$ Departamento de Química, Universidade de Aveiro.

"CIQ, Departamento de Química, Faculdade de Ciências da Universidade do Porto. ethanol, and butanol from fermentation broths as well as in the removal of organic contaminants from aqueous waste streams has been studied already. ${ }^{6,7}$ Furthermore, it was shown recently that water-immiscible $\left[\mathrm{BF}_{4}\right]$-based ILs can be used successfully in the extraction of metal ions such as nickel, zinc, cadmium, and mercury from wastewater. ${ }^{8}$ A detailed understanding of the interplay of ILs structural variations and process conditions (such as temperature) in the phase behavior of water and ILs systems is required in order to optimize these separation processes.

The knowledge of ILs and water mutual solubilities is also of significant importance in the evaluation of their environmental risk. Although ILs are generally referred to as "green" solvents, studies about their toxicity and biodegradability are still scarce. In fact, although they cannot contribute to air pollution because of their negligible vapor pressures, some of them present a nonnegligible solubility in water, thus leading to environmental problems. Once in the environment, the IL's ecotoxicity can be directly linked to their lipophilicity. ${ }^{9-12}$ Because biological membranes can be regarded as nonpolar interfaces, the IL's toxicity in the aquatic species is driven by the ions ability to disrupt this membrane by a hydrophobic-ionic adsorption phenomenon at the cell-membrane interface. ${ }^{13}$ Therefore, hydrophobic ILs tend to accumulate in biological membranes and thus the toxicity will increase with their hydrophobic character. The knowledge of ILs and water mutual solubilities can provide 
not only a way to evaluate their dispersion on the ecosystem but also their effect upon the individual microorganisms.

The quantification of the amount of water in the ionic liquid phase is also important because it significantly affects their pure physical properties such as viscosities, densities, and surface tensions. ${ }^{14-16}$ Water may also act as a cosolvent, for example, increasing the mutual solubilities between alcohols and ILs, or as an antisolvent, reducing the solubility of gases in ILs. ${ }^{17-20}$ The presence of water can also affect the rates and selectivity of reactions involving or carried in ILs. ${ }^{21}$

Despite the importance of the knowledge of the mutual solubilities of ILs and water, only few scattered publications reporting measurements are available $7,17,22-35$ and only one overview of the mutual solubilities between water and imidazolium-based ILs has been published so far. ${ }^{36}$ In this work, a rigorous and systematic experimental study of the mutual solubilites between ILs and water from 288.15 to $318.15 \mathrm{~K}$ at atmospheric pressure was conducted for imidazolium-, pyridinium-, pyrrolidinium-, and piperidinium-based cations and bis(trifluoromethylsulfonyl)imide-, hexafluorophosphate-, and tricyanomethane-based anions ILs. The main goal of this study is to determine the impact of the ionic liquids' structural modifications, such as the cation family, the cation alkyl chain length, the number of substitutions at the cation, and the anion identity influence in their liquid-liquid phase behavior with water. Furthermore, the behavior of these mixtures at the molecular level was studied through the analysis of the molar solution thermodynamic properties.

The COSMO-RS, conductor-like screening model for real solvents, is a novel method for the prediction of thermophysical properties of fluids based on unimolecular quantum calculations. ${ }^{37-41}$ The application of COSMO-RS to the LLE description of ILs and alcohols, hydrocarbons, ethers, ketones, and water systems has been carried out already. ${ }^{42-48}$ This model has proven to be a valuable tool in the prediction of properties of systems involving ILs because the traditional approaches such as the structure-interpolating group-contribution methods (GCMs), equations of state (EoS), and usual correlations require a large experimental database prior to their effective use, which is a restrictive factor considering the huge number of possible IL combinations. The performance of this predictive method is analyzed in the prediction of water-IL binary systems which have also been measured experimentally. COSMOS-RS proves to be, at least qualitatively, an a priori method of selection for predicting the water-IL binary system's phase behavior.

\section{Experimental Section}

Materials. The mutual solubilities with water were studied for the following ILs: 1-butyl-3-methylimidazolium hexafluorophosphate, $\left[\mathrm{C}_{4} \mathrm{mim}\right]\left[\mathrm{PF}_{6}\right]$, 1-hexyl-3-methylimidazolium hexafluorophosphate, $\left[\mathrm{C}_{6} \mathrm{mim}\right]\left[\mathrm{PF}_{6}\right]$, 1-methyl-3-octylimidazolium hexafluorophosphate, $\left[\mathrm{C}_{8} \mathrm{mim}\right]\left[\mathrm{PF}_{6}\right]$, 1-butyl-2,3-dimethylimidazolium hexafluorophosphate, $\left[\mathrm{C}_{4} \mathrm{C}_{1} \mathrm{mim}\right]\left[\mathrm{PF}_{6}\right]$, 1-butyl-3-methylimidazolium tricyanomethane $\left[\mathrm{C}_{4} \mathrm{mim}\right]\left[\mathrm{C}(\mathrm{CN})_{3}\right]$, 3-methyl-1propylpyridinium bis(trifluoromethylsulfonyl)imide, [ $\left.\mathrm{C}_{3} \mathrm{mpy}\right]-$ $\left[\mathrm{Tf}_{2} \mathrm{~N}\right]$, 1-methyl-1-propylpyrrolidinium bis(trifluoromethylsulfonyl)imide, $\left[\mathrm{C}_{3} \mathrm{mpyr}\right]\left[\mathrm{Tf}_{2} \mathrm{~N}\right]$, 1-butyl-1-methylpyrrolidinium bis(trifluoromethylsulfonyl)imide $\left[\mathrm{C}_{4} \operatorname{mpyr}\right]\left[\mathrm{Tf}_{2} \mathrm{~N}\right]$, and 1methyl-1-propylpiperidinium bis(trifluoromethylsulfonyl)imide, $\left[\mathrm{C}_{3}\right.$ mpip $]\left[\mathrm{Tf}_{2} \mathrm{~N}\right]$. The $\left[\mathrm{C}_{4} \mathrm{mim}\right]\left[\mathrm{PF}_{6}\right]$ and $\left[\mathrm{C}_{6} \mathrm{mim}\right]\left[\mathrm{PF}_{6}\right]$ were acquired from IoLiTec with mass fraction purities $>99 \%$. The bromide impurity mass fraction for $\left[\mathrm{C}_{4} \mathrm{mim}\right]\left[\mathrm{PF}_{6}\right]$ is $85 \mathrm{ppm}$ and for $\left[\mathrm{C}_{6} \mathrm{mim}\right]\left[\mathrm{PF}_{6}\right]$ is $<100 \mathrm{ppm}$. The $\left[\mathrm{C}_{8} \mathrm{mim}\right]\left[\mathrm{PF}_{6}\right]$ and $\left[\mathrm{C}_{4} \mathrm{C}_{1} \mathrm{mim}\right]\left[\mathrm{PF}_{6}\right]$ were acquired from Solchemar with mass fraction purities $>99 \%$. The chloride mass fraction content in both ILs is $<80 \mathrm{ppm}$. The $\left[\mathrm{C}_{4} \mathrm{mim}\right]\left[\mathrm{C}(\mathrm{CN})_{3}\right]$ was acquired from Merck with a mass fraction purity $\geq 99 \%$ and a mass fraction of chloride ion $\leq 1000 \mathrm{ppm}$. The $\left[\mathrm{C}_{3} \mathrm{mpy}\right]\left[\mathrm{Tf}_{2} \mathrm{~N}\right]$, $\left[\mathrm{C}_{3} \mathrm{mpyr}\right]-$ $\left[\mathrm{Tf}_{2} \mathrm{~N}\right],\left[\mathrm{C}_{4} \mathrm{mpyr}\right]\left[\mathrm{Tf}_{2} \mathrm{~N}\right]$, and $\left[\mathrm{C}_{3} \mathrm{mpip}\right]\left[\mathrm{Tf}_{2} \mathrm{~N}\right]$ were acquired from IoLiTec with mass fraction purities $>99 \%$ and a bromide impurity mass fraction $<100 \mathrm{ppm}$.

To reduce the water and volatile compounds content to negligible values, we dried IL individual samples under constant agitation at vacuum $(0.1 \mathrm{~Pa})$ and moderate temperature (353 $\mathrm{K}$ ) for a minimum of $48 \mathrm{~h}$. After this procedure, we checked the purity of each ionic liquid by ${ }^{1} \mathrm{H},{ }^{13} \mathrm{C}$, and ${ }^{19} \mathrm{~F}$ NMR.

The water used was double-distilled, passed by a reverse osmosis system, and further treated with a MilliQ plus 185 water purification apparatus. It has a resistivity of $18.2 \mathrm{M} \Omega \cdot \mathrm{cm}$, a TOC smaller than $5 \mu \mathrm{g} \cdot \mathrm{L}^{-1}$, and it is free of particles greater than $0.22 \mu \mathrm{m}$. The analyte used for the coulometric Karl Fischer titration was Hydranal - Coulomat AG from Riedel-de Haën.

Experimental Procedure. The mutual solubility measurements between water and ILs were carried out at temperatures from 288.15 to $318.15 \mathrm{~K}$ and at atmospheric pressure. In the case of the water solubility in $\left[\mathrm{C}_{4} \mathrm{C}_{1} \mathrm{mim}\right]\left[\mathrm{PF}_{6}\right]$, the temperature range was from 303.15 to $318.15 \mathrm{~K}$ because of the high melting point of this IL. The IL and the water phases were initially agitated vigorously and allowed to reach the saturation equilibrium by the separation of both phases in $22 \mathrm{~mL}$ glass vials for at least $48 \mathrm{~h}$. This period proved to be the minimum time required to guarantee a complete separation of the two phases and that no further variations in mole fraction solubilities occurred.

The temperature was maintained by keeping the glass vials containing the phases in equilibrium inside an aluminum block specially designed for this purpose, which is placed in an isolated air bath capable of maintaining the temperature within \pm 0.01 $\mathrm{K}$. The temperature control was achieved with a PID temperature controller driven by a calibrated Pt100 (class 1/10) temperature sensor inserted in the aluminum block. In order to reach temperatures below room temperature, we coupled a Julabo circulator, model F25-HD, to the overall oven system allowing the passage of a thermostatized fluid flux around the aluminum block. The solubility of water in the IL-rich phase was determined using a Metrohm 831 Karl Fischer (KF) coulometer, and the solubility of ILs in the water-rich phase was determined by UV spectroscopy using a SHIMADZU UV-1700 PharmaSpec Spectrometer, at a wavelength of 211 or $266 \mathrm{~nm}$, using calibration curves established previously. These wavelengths were found to be the maximum UV absorption lengths for the imidazolium- and pyridinium-based cations studied, respectively. Both rich phases were sampled at each temperature from the equilibrium vials using glass syringes maintained dry and at the same temperature of the measurements. For the IL-rich phase, samples of $\sim 0.1$ to $0.2 \mathrm{~g}$ were taken and injected directly into the KF coulometric titrator, whereas for the water-rich phase, samples of $\sim 0.3$ to $1.0 \mathrm{~g}$ were taken and diluted by a factor ranging from $1: 50$ to $1: 1000(\mathrm{v}: \mathrm{v})$ in ultrapure water, depending on the solubility of the IL under study. The high precision and accuracy of this method can be linked not only to the gravimetric procedure but also to the dilutions of the samples of the water-rich phase, avoiding phase split when working at temperatures different from room temperature. The mutual solubility results at each individual temperature are an average of at least five independent measurements.

Because it was already shown that $\left[\mathrm{PF}_{6}\right]$-based ILs can decompose in acidic medium, reacting with water and producing 
the toxic fluoridric acid, ${ }^{49}$ a study of the possible hydrolysis of these ILs during the equilibration with water at the maximum temperature used in this work was carried out using electrospray ionization mass (ESI-MS) and tandem mass spectra (ESI-MSMS). The mass spectra were acquired with a Micromass Quattro LC triple quadrupole mass spectrometer operating in the negative ion mode. The source and desolvation temperatures were 353 and $423 \mathrm{~K}$, respectively. The capillary and the cone voltage were 2600 and $30 \mathrm{~V}$, respectively. Nitrogen was used as the nebulization gas. ESI-MS-MS spectra were acquired by selecting the precursor ion with the first quadrupole, performing collisions with argon at energies of $15 \mathrm{eV}$ in the second quadrupole, followed by mass analysis of product ions on the third quadrupole. Both rich phases were introduced at a 10 $\mu \mathrm{L} \cdot \min ^{-1}$ flow rate using methanol as the eluent solvent.

Mass spectrometry measurements have also been carried out to establish the relative strength of the cation-anion interaction for the ionic liquids studied. For that purpose, the pure ionic liquids were diluted in acetonitrile at a concentration of $(1.5 \times$ $\left.10^{-4}\right) \mathrm{mol} \cdot \mathrm{L}^{-1}$. ESI-MS and ESI-MS-MS were acquired with a Micromass QTOF 2 operating in the positive and negative ion modes. Source and desolvation temperatures were 353 and 373 $\mathrm{K}$, respectively. Capillary and cone voltage were 2600 and 25 $\mathrm{V}$, respectively. Nitrogen was used as the nebulization gas. ESIMS-MS spectra were acquired by selecting the precursor ion ([cation...anion...cation $]^{+}$or [anion...cation...anion $]^{-}$) with the quadrupole, performing collisions with argon at energies of 10 $\mathrm{eV}$ in the hexapole, followed by mass analysis of product ions by the TOF analyzer. The ionic liquid solutions were introduced at a $10 \mu \mathrm{L} \cdot \mathrm{min}^{-1}$ flow rate.

Thermodynamic Functions. The dissolution of a liquid into another is associated with changes in the thermodynamic functions, such as the standard molar Gibbs energy $\left(\Delta_{\mathrm{sol}} G_{\mathrm{m}}^{\mathrm{o}}\right)$, the standard molar enthalpy $\left(\Delta_{\mathrm{sol}} H_{\mathrm{m}}^{\mathrm{o}}\right)$ and the standard molar entropy $\left(\Delta_{\mathrm{sol}} S_{\mathrm{m}}^{\mathrm{o}}\right)$ of solution, that can be determined from the temperature dependence of the experimental solubility data. These thermodynamic functions are associated with the changes that occur in the solute neighborhood when one solute molecule is transferred from an ideal gas phase to a dilute ideal solution and can be calculated according to eqs $1-3.50$

$$
\begin{gathered}
\Delta_{\mathrm{sol}} G_{m}^{\mathrm{o}}=-R T \ln \left(x_{2}\right)_{p} \\
\frac{\Delta_{\mathrm{sol}} H_{m}^{\mathrm{o}}}{R T^{2}}=\left(\frac{\partial \ln x_{2}}{\partial T}\right)_{p} \\
\Delta_{\mathrm{sol}} S_{m}^{\mathrm{o}}=R\left(\frac{\partial \ln x_{2}}{\partial \ln T}\right)_{p}
\end{gathered}
$$

where $x_{2}$ is the mole fraction solubility of the solute, $R$ is the ideal gas constant, $T$ is the temperature, and the subscript $p$ indicates that the process takes place at constant pressure. The subscript $m$ refers to the molar quantity.

\section{Results and Discussion}

[PF 6 -based ILs Hydrolysis Studies. All of the $\left[\mathrm{PF}_{6}\right]$-based ILs were tested to check if hydrolysis occurs at the experimental conditions used for the mutual solubility measurements. Both rich phases were collected and injected after $48 \mathrm{~h}$ and after 2 years at equilibrium at $318.15 \mathrm{~K}$. The mass spectra of the water and ionic liquid rich phases did not reveal any of the ions described previously in the literature ${ }^{51,52}$ as a result of the hexafluorophosphate anion hydrolysis, namely, $m / z 123\left[\mathrm{~F}_{4} \mathrm{PO}\right]^{-}$ and $m / z, 101\left[\mathrm{~F}_{2} \mathrm{PO}_{2}\right]^{-}$. Although the fluoride anion was also absent in all of the sample spectra, an ion at $\mathrm{m} / \mathrm{z}, 51$ assigned by MS-MS to $[\mathrm{CH} 3 \mathrm{OH} \cdot \mathrm{F}]^{-}$was observed for all of the samples analyzed, with a maximum abundance, in the IL-rich phase, of $0.35 \%$ relative to the base peak which is $m / z, 145\left[\mathrm{PF}_{6}\right]^{-}$. From the results obtained, it can be concluded that no significant hydrolysis occurs under the experimental conditions used for the mutual solubility measurements.

Relative Cation-Anion Interaction Strength. Mass spectrometry measurements have been carried out as described above to establish the relative interaction strength, which is a combined result of electrostatic, hydrogen bonding, polar, and dispersion forces between the cation and the anion in the studied ILs. From the mass spectra interpretation, a higher abundance of the cation $\mathrm{C}^{+}$in the ESI-MS-MS spectra of the heterodimer [C1...A...C2 $]^{+}$ implies a stronger interaction between the cation $\mathrm{C}_{2}{ }^{+}$and the anion $\mathrm{A}^{-}$. The same line of thought is valid for the anion. ${ }^{53}$ The ESI-MS-MS spectra results for the ILs binary equimolar mixtures used to form the clusters show that the relative strength of cation-anion interaction strength observed both in $\left[\mathrm{C}_{1} \ldots \mathrm{BF}_{4} \ldots \mathrm{C} 2\right]^{+}$ and in $\left[\mathrm{C} 1 \ldots \mathrm{PF}_{6} \ldots \mathrm{C} 2\right]^{+}$for the imidazolium-based cations increases in the order $\left[\mathrm{C}_{4} \mathrm{C}_{1} \mathrm{mim}\right]<\left[\mathrm{C}_{8} \mathrm{mim}\right]<\left[\mathrm{C}_{6} \mathrm{mim}\right]<$ $\left[\mathrm{C}_{4} \mathrm{mim}\right]$. The same dependence of the cation-anion interaction with the alkyl chain length was observed for the pyrrolidiniumbased ILs. When comparing the different cation families using the cation $\left[\mathrm{C} 1 \ldots \mathrm{Tf}_{2} \mathrm{~N} \ldots \mathrm{C} 2\right]^{+}$, the interaction strength increases in the order $\left[\mathrm{C}_{3} \mathrm{mpip}\right]<\left[\mathrm{C}_{3} \mathrm{mpyr}\right]<\left[\mathrm{C}_{3} \mathrm{mpy}\right]<\left[\mathrm{C}_{3} \mathrm{mim}\right]$. For the anion influence in the cation-anion interaction, the heterodimer $\left[\mathrm{A} 1 \ldots \mathrm{C}_{4} \mathrm{mim} . . \mathrm{A} 2\right]^{-}$ESI-MS-MS spectra were analyzed and the results indicate an increase in the order $\left[\mathrm{Tf}_{2} \mathrm{~N}\right]<$ $\left[\mathrm{C}(\mathrm{CN})_{3}\right]<\left[\mathrm{PF}_{6}\right]$. The relative strength of the cation-anion interaction decreases as the alkyl side chain length increases for both imidazolium- and pyrrolidinium-based cation families studied because of an increase in the hydrogen-to-fluorine distance with the alkyl chain length. Furthermore, the inclusion of the third substitution in the imidazolium cation eliminates the most-acidic hydrogen at the $\mathrm{C} 2$ position, therefore reducing the ability of hydrogen bonding between the imidazolium cation and the anion. As for the anion influence on the relative interaction strength, a general trend can be established between the cation-anion interaction and the anion molar volumes: the former decreases as the molar volume increases. ${ }^{16,54}$ The relevance of these results to the understanding of the measured mutual solubilities is discussed below.

Mutual Solubilities Results. The mutual solubilities between the imidazolium- and pyridinium-based ILs and water were measured in the temperature range from 288.15 to $318.15 \mathrm{~K}$ and at atmospheric pressure. Because of its high melting point, the solubility of water in $\left[\mathrm{C}_{4} \mathrm{C}_{1} \mathrm{mim}\right]\left[\mathrm{PF}_{6}\right]$ was only measured for temperatures above $303.15 \mathrm{~K}$. The solubilities of pyrrolidinium- and piperidinium-based ILs in water were not measured because of the incapability to quantify these based compounds correctly with the equipment available.

The experimental solubility results measured here are compared with the available literature data ${ }^{6,7,22,23,26-28}$ in Figure 1. There are large differences among different authors, especially in the water-rich side, which can be directly related to the accuracy in the measurements of very low solubilities. However, a close agreement between our data and the data reported by Najdanovic-Visak et al. ${ }^{25}$ for $\left[\mathrm{C}_{4} \mathrm{mim}\right]\left[\mathrm{PF}_{6}\right]$ was observed. In the IL-rich side, smaller relative deviations exist between different authors, which can also be linked to the larger mole fraction solubility measurements. 


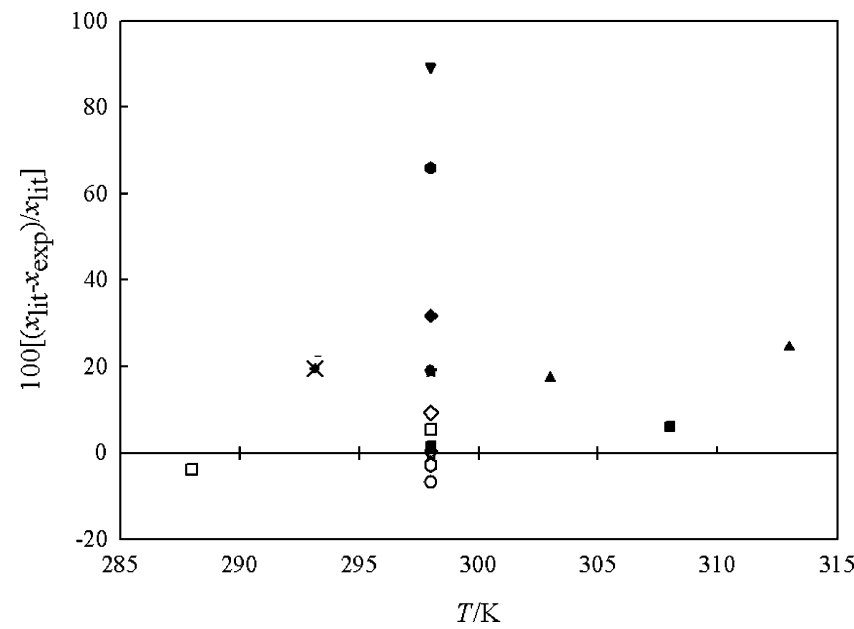

Figure 1. Relative deviations between the experimental mole fraction solubility of water in ILs (empty symbols) and ILs in water (full symbols) obtained in this work $\left(x_{\text {exp }}\right)$ and those reported in the literature $\left(x_{\mathrm{lit}}\right)$ as a function of temperature: $\diamond,\left[\mathrm{C}_{8} \mathrm{mim}\right]\left[\mathrm{PF}_{6}\right]$, Fadeev et al. ${ }^{6} \nabla$, $\left[\mathrm{C}_{4} \mathrm{mim}\right]\left[\mathrm{PF}_{6}\right], \mathrm{McF}$ arlane et al. ${ }^{7}$ 放, $\left[\mathrm{C}_{4} \mathrm{mim}\right]\left[\mathrm{PF}_{6}\right]$, Anthony et al.;22 $\mathrm{O},\left[\mathrm{C}_{8} \mathrm{mim}\right]\left[\mathrm{PF}_{6}\right]$, Anthony et al. ${ }^{22} \Delta,\left[\mathrm{C}_{4} \mathrm{mim}\right]\left[\mathrm{PF}_{6}\right]$, Wong et al.; ${ }^{23}$ $\square,\left[\mathrm{C}_{4} \mathrm{mim}\right]\left[\mathrm{PF}_{6}\right]$, Najdanovic-Visak et al.;26,$-\left[\mathrm{C}_{4} \mathrm{mim}\right]\left[\mathrm{PF}_{6}\right]$, Alfassi et al.; ${ }^{27}+,\left[\mathrm{C}_{4} \mathrm{mim}\right]\left[\mathrm{PF}_{6}\right]$, Shvedene et al.; ${ }^{28} \times,\left[\mathrm{C}_{4} \mathrm{C}_{1} \mathrm{mim}\right]\left[\mathrm{PF}_{6}\right]$, Shvedene et al. ${ }^{28}$

The experimental solubility data measured and the respective standard deviations are presented in Tables 1 and 2. In general terms, it can be observed that, for all of the studied ILs, the miscibility of both phases increases with temperature. Note that all of the studied ILs are known as "hydrophobic" but the water solubility results indicate that they are substantially "hygroscopic". The mole fraction solubility of ILs in water ranges from $10^{-3}$ to $10^{-4}$, and the water in ILs is on the order of $10^{-1}$. Thus, although the water-rich phase can be considered almost as a pure phase with the dissolved IL at infinite dilution, the ILrich phase cannot be considered as a nearly pure IL phase.

The results obtained for all of the studied ILs show a large difference in the mole fraction solubilities of water in ILs, ranging from 0.186 for the $\left[\mathrm{C}_{4} \mathrm{mpyr}\right]\left[\mathrm{Tf}_{2} \mathrm{~N}\right]$ to 0.889 , or almost complete miscibility, for $\left[\mathrm{C}_{4} \mathrm{mim}\right]\left[\mathrm{C}(\mathrm{CN})_{3}\right]$. The inspection of Tables 1 and 2 clearly shows that the anion plays the dominant role in the mutual solubilities followed by the cation alkyl chain length and the cation family, which have a secondary influence.

The experimental results obtained in this work and the reported mutual solubilities of water with $\left[\mathrm{C}_{3} \operatorname{mim}\right]\left[\mathrm{Tf}_{2} \mathrm{~N}\right]^{35}$ show that there is a hydrophobic tendency increase due to the cation family from $\left[\mathrm{C}_{n} \mathrm{mim}\right]<\left[\mathrm{C}_{n} \mathrm{mpy}\right] \leq\left[\mathrm{C}_{n} \mathrm{mpyr}\right]<\left[\mathrm{C}_{n} \mathrm{mpip}\right]$. The imidazolium-based cations present the higher solubility of water, followed by the pyridinium-, the pyrrolidinium-, and at last the piperidinium-based ILs. The higher water solubility in the imidazolium and pyridinium-based ILs when compared with the pyrrolidinium and piperidinium-based ILs seems to be due to the interaction of the water with the $\pi$ systems of those former cations while no electrons are available for privileged interaction on the latter. These mutual solubility dependencies follow the same trend as the ESI-MS-MS relative interactions, thus showing how these mutual solubilities of ionic liquids with water are dependent on the cation/anion ability to develop strong interactions with other solutes or solvents. As for the effect of the alkyl side chain length for both the imidazolium and pyrrolidinium-based ILs, it can be seen that there is a decrease in the solubility with water with the increase of the alkyl chain length of the cation and thus an increase in the ILs hydrophobic tendency. These results are consistent with the ESI-MS-MS results presented above. The higher the relative cation-anion interaction strength, the higher the interactions with water.

The replacement of the most-acidic hydrogen at the $\mathrm{C} 2$ position in the imidazolium cation by a methyl group induces different changes on the two phases. It leads to a strong decrease of the water solubility to a value closer to that obtained for $\left[\mathrm{C}_{8} \mathrm{mim}\right]\left[\mathrm{PF}_{6}\right]$. The hydrogen bonding between water with the acidic hydrogen of the imidazolium cation clearly has a large influence in the liquid-liquid phase behavior between imidazolium-based ILs and water. Alternatively, the solubility of $\left[\mathrm{C}_{4} \mathrm{C}_{1} \mathrm{mim}\right]\left[\mathrm{PF}_{6}\right]$ in water falls between that of $\left[\mathrm{C}_{4} \mathrm{mim}\right]\left[\mathrm{PF}_{6}\right]$ and $\left[\mathrm{C}_{6} \mathrm{mim}\right]\left[\mathrm{PF}_{6}\right]$, indicating that the hydrogen bonding on the water-rich phase of the equilibrium is not one of the most relevant factors determining the solubility, with the cation size being more important. This effect of substituting the most-acidic hydrogen at the imidazolium cation was already verified by Crosthwaite et al. ${ }^{24,55,56}$ in alcohols-IL binary system phase behavior. The authors ${ }^{24,55,56}$ also found that by replacing the C2 hydrogen with a methyl group the ability of the cation to hydrogen bond with the alcohol was greatly diminished.

When inferring the anion influence, the comparison of the results obtained in this work with a previous work for [ $\left.\mathrm{C}_{4} \mathrm{mim}\right]$ $\left[\mathrm{Tf}_{2} \mathrm{~N}\right]^{35}$ at the same experimental conditions enables the conclusion that there is an increase in the hydrophobic tendency due to the anion following the order $\left[\mathrm{C}(\mathrm{CN})_{3}\right]<\left[\mathrm{PF}_{6}\right]<\left[\mathrm{Tf}_{2} \mathrm{~N}\right]$. This trend does not follow the relative interaction between cation and anion observed in the ESI-MS-MS studies. A possible explanation is that mass spectrometry results reflect the total gas-phase interactions where the Coulombic charge interactions are quite strong and dominate other interactions. Although for cations this seems to correlate well with the solvation with water, for the anion the solvation mechanism seem to be far more complex and not possible to correlate with the anion-cation interaction strength at the gas phase.

Temperature Dependence of Water in ILs Solubility. The integration of eq 1, assuming that in the temperature range studied, $\Delta_{\text {sol }} H_{\mathrm{m}}^{\mathrm{o}}$ can be considered temperature-independent, leads to eq 4 , which proved to correlate the experimental solubility data of water in ILs accurately

$$
\ln x_{\mathrm{w}}=A+\frac{B}{(T / K)}
$$

where $x_{\mathrm{w}}$ is the mole fraction solubility of the water in IL, $T$ is the temperature, and $A$ and $B$ are correlation parameters. The correlation constants obtained from the fitting of the water solubility experimental data are presented in Table 3 . The proposed correlation shows a relative maximum average deviation from the experimental mole fraction data of $2 \%$.

Because the solubility of water in all of the studied ILs is well above of what could be considered infinite dilution, the associated molar thermodynamic functions of solution were not determined.

Temperature Dependence of ILs in Water Solubility. The correlation of the experimental solubility of ILs in water data was carried out using eq 5 , which showed to be capable of describing the temperature dependence of the solubility of organics in water

$$
\ln x_{\mathrm{IL}}=C+\frac{D}{(T / K)}+E \ln (T / K)
$$

where $x_{\mathrm{IL}}$ is the mole fraction solubility of the IL in water, $T$ is the temperature, and $C, D$, and $E$ are correlation parameters. These correlation parameters and the respective standard devia- 
TABLE 1: Experimental Mole Fraction Solubility of Water in ILs, $x_{\mathrm{w}}$, as a Function of Temperature

\begin{tabular}{|c|c|c|c|c|c|c|c|c|c|}
\hline & $\begin{array}{c}{\left[\mathrm{C}_{4} \operatorname{mim}\right]} \\
{\left[\mathrm{PF}_{6}\right]}\end{array}$ & $\begin{array}{c}{\left[\mathrm{C}_{6} \operatorname{mim}\right]} \\
{\left[\mathrm{PF}_{6}\right]}\end{array}$ & $\begin{array}{c}{\left[\mathrm{C}_{8} \operatorname{mim}\right]} \\
{\left[\mathrm{PF}_{6}\right]}\end{array}$ & $\begin{array}{c}{\left[\mathrm{C}_{4} \mathrm{C}_{1} \operatorname{mim}\right]} \\
{\left[\mathrm{PF}_{6}\right]}\end{array}$ & $\begin{array}{l}{\left[\mathrm{C}_{4} \mathrm{mim}\right]} \\
{\left[\mathrm{C}(\mathrm{CN})_{3}\right]}\end{array}$ & $\begin{array}{c}{\left[\mathrm{C}_{3} \mathrm{mpy}\right]} \\
{\left[\mathrm{Tf}_{2} \mathrm{~N}\right]}\end{array}$ & $\begin{array}{c}{\left[\mathrm{C}_{3} \mathrm{mpyr}\right]} \\
{\left[\mathrm{Tf}_{2} \mathrm{~N}\right]}\end{array}$ & $\begin{array}{c}{\left[\mathrm{C}_{4} \mathrm{mpyr}\right]} \\
{\left[\mathrm{Tf}_{2} \mathrm{~N}\right]}\end{array}$ & $\begin{array}{c}{\left[\mathrm{C}_{3} \mathrm{mpip}\right]} \\
{\left[\mathrm{Tf}_{2} \mathrm{~N}\right]}\end{array}$ \\
\hline$T / \mathrm{K}$ & $\left(x_{\mathrm{w}} \pm \sigma^{a}\right)$ & $\left(x_{\mathrm{w}} \pm \sigma^{a}\right)$ & $\left(x_{\mathrm{w}} \pm \sigma^{a}\right)$ & $\left(x_{\mathrm{W}} \pm \sigma^{a}\right)$ & $\left(x_{\mathrm{w}} \pm \sigma^{a}\right)$ & $\left(x_{\mathrm{w}} \pm \sigma^{a}\right)$ & $\left(x_{\mathrm{w}} \pm \sigma^{a}\right)$ & $\left(x_{\mathrm{w}} \pm \sigma^{a}\right)$ & $\left(x_{\mathrm{w}} \pm \sigma^{a}\right)$ \\
\hline 288.15 & $0.229 \pm 0.003$ & $0.196 \pm 0.003$ & $0.172 \pm 0.003$ & & $0.844 \pm 0.005$ & 0.001 & 0.004 & $0.186 \pm 0.004$ & 0.188 \\
\hline 293.15 & $0.251 \pm 0.001$ & $0.209 \pm 0.001$ & $0.185 \pm 0.002$ & & $0.848 \pm 0.003$ & $0.226 \pm 0.004$ & $0.220 \pm 0.001$ & $0.199 \pm 0.004$ & 0.199 \\
\hline 298.15 & $0.272 \pm 0.003$ & $0.229 \pm 0.003$ & $0.205 \pm 0.004$ & & $0.857 \pm 0.009$ & $0.236 \pm 0.004$ & $0.233 \pm 0.004$ & $0.211 \pm 0.001$ & $0.212 \pm 0.003$ \\
\hline 303.15 & $0.293 \pm 0.004$ & $0.250 \pm 0.004$ & $0.217 \pm 0.004$ & $0.219 \pm 0.003$ & $0.863 \pm 0.005$ & $0.260 \pm 0.006$ & $0.254 \pm 0.001$ & $0.233 \pm 0.004$ & $0.231 \pm 0.004$ \\
\hline 308.15 & $0.303 \pm 0.004$ & $0.267 \pm 0.004$ & $0.229 \pm 0.006$ & $0.237 \pm 0.007$ & $0.870 \pm 0.002$ & $0.270 \pm 0.003$ & $0.268 \pm 0.004$ & $0.244 \pm 0.005$ & $0.255 \pm 0.005$ \\
\hline 313.15 & $0.333 \pm 0.004$ & $0.288 \pm 0.004$ & $0.250 \pm 0.004$ & $0.252 \pm 0.006$ & $0.879 \pm 0.005$ & $0.292 \pm 0.001$ & $0.290 \pm 0.004$ & $0.263 \pm 0.003$ & $0.272 \pm 0.002$ \\
\hline 318.15 & $0.348 \pm 0.004$ & $0.303 \pm 0.004$ & $0.257 \pm 0.004$ & $0.263 \pm 0.004$ & $0.889 \pm 0.004$ & $0.310 \pm 0.005$ & $0.299 \pm 0.007$ & $0.282 \pm 0.004$ & $0.289 \pm 0.005$ \\
\hline
\end{tabular}

${ }^{a}$ Standard deviation.

TABLE 2: Experimental Mole Fraction Solubility of ILs in Water, $x_{\mathrm{IL}}$, as a Function of Temperature

\begin{tabular}{ccccccc}
\hline & {$\left[\mathrm{C}_{4} \mathrm{mim}\right]\left[\mathrm{PF}_{6}\right]$} & {$\left[\mathrm{C}_{6} \mathrm{mim}\right]\left[\mathrm{PF}_{6}\right]$} & {$\left[\mathrm{C}_{8} \mathrm{mim}\right]\left[\mathrm{PF}_{6}\right]$} & {$\left[\mathrm{C}_{4} \mathrm{C}_{1} \mathrm{mim}\right]\left[\mathrm{PF}_{6}\right]$} & {$\left[\mathrm{C}_{4} \mathrm{mim}\right]\left[\mathrm{C}(\mathrm{CN})_{3}\right]$} & {$\left[\mathrm{C}_{3} \mathrm{mpy}\right]\left[\mathrm{Tf}{ }_{2} \mathrm{~N}\right]$} \\
\hline$T / \mathrm{K}$ & $10^{3}\left(x_{\mathrm{IL}} \pm \sigma^{a}\right)$ & $10^{4}\left(x_{\mathrm{IL}} \pm \sigma^{a}\right)$ & $10^{4}\left(x_{\mathrm{IL}} \pm \sigma^{a}\right)$ & $10^{4}\left(x_{\mathrm{IL}} \pm \sigma^{a}\right)$ & $10^{3}\left(x_{\mathrm{IL}} \pm \sigma^{a}\right)$ & $10^{4}\left(x_{\mathrm{IL}} \pm \sigma^{a}\right)$ \\
\hline 288.15 & $1.01 \pm 0.06$ & $3.54 \pm 0.01$ & $1.13 \pm 0.01$ & $7.18 \pm 0.01$ & $5.62 \pm 0.01$ & $3.51 \pm 0.04$ \\
293.15 & $1.10 \pm 0.01$ & $3.92 \pm 0.01$ & $1.20 \pm 0.02$ & $7.59 \pm 0.02$ & $5.75 \pm 0.07$ & $3.66 \pm 0.02$ \\
298.15 & $1.21 \pm 0.01$ & $4.34 \pm 0.02$ & $1.27 \pm 0.03$ & $8.17 \pm 0.04$ & $6.22 \pm 0.03$ & $3.75 \pm 0.02$ \\
303.15 & $1.29 \pm 0.01$ & $4.68 \pm 0.03$ & $1.46 \pm 0.04$ & $8.74 \pm 0.06$ & $6.83 \pm 0.01$ & $3.90 \pm 0.02$ \\
308.15 & $1.43 \pm 0.04$ & $5.04 \pm 0.02$ & $1.59 \pm 0.02$ & $9.97 \pm 0.04$ & $7.38 \pm 0.01$ & $4.27 \pm 0.04$ \\
313.15 & $1.58 \pm 0.01$ & $5.59 \pm 0.01$ & $1.76 \pm 0.01$ & $10.84 \pm 0.03$ & $7.99 \pm 0.02$ & $4.42 \pm 0.04$ \\
318.15 & $1.76 \pm 0.02$ & $6.78 \pm 0.01$ & $2.03 \pm 0.02$ & $11.51 \pm 0.08$ & $9.56 \pm 0.05$ & $4.76 \pm 0.09$
\end{tabular}

${ }^{a}$ Standard deviation.

TABLE 3: Correlation Parameters for the Mole Fraction Solubility of Water in ILs and ILs in Water as a Function of Temperature Using Equations 4 and 5, Respectively

\begin{tabular}{|c|c|c|c|c|c|}
\hline IL & $A \pm \sigma^{a}$ & $\left(B \pm \sigma^{a}\right) / \mathrm{K}$ & $C \pm \sigma^{a}$ & $\left(D \pm \sigma^{a}\right) / \mathrm{K}$ & $E \pm \sigma^{a}$ \\
\hline$\left[\mathrm{C}_{4} \mathrm{mim}\right]\left[\mathrm{PF}_{6}\right]$ & $2.92 \pm 0.17$ & $-1261 \pm 50$ & $-223 \pm 47$ & $8345 \pm 2137$ & $33 \pm 7$ \\
\hline$\left[\mathrm{C}_{6} \mathrm{mim}\right]\left[\mathrm{PF}_{6}\right]$ & $3.13 \pm 0.11$ & $-1373 \pm 32$ & $-454 \pm 193$ & $18575 \pm 8728$ & $67 \pm 29$ \\
\hline$\left[\mathrm{C}_{8} \mathrm{mim}\right]\left[\mathrm{PF}_{6}\right]$ & $2.61 \pm 0.17$ & $-1257 \pm 52$ & $-413 \pm 87$ & $16703 \pm 3920$ & $61 \pm 13$ \\
\hline$\left[\mathrm{C}_{4} \mathrm{C}_{1} \mathrm{mim}\right]\left[\mathrm{PF}_{6}\right]$ & $2.32 \pm 0.21$ & $-1160 \pm 84$ & $-142 \pm 125$ & $4772 \pm 5661$ & $21 \pm 19$ \\
\hline$\left[\mathrm{C}_{4} \mathrm{mim}\right]\left[\mathrm{C}(\mathrm{CN})_{3}\right]$ & $0.378 \pm 0.029$ & $-159 \pm 9$ & $-550 \pm 135$ & $23250 \pm 6111$ & $82 \pm 20$ \\
\hline$\left[\mathrm{C}_{3} \mathrm{mpy}\right]\left[\mathrm{Tf}_{2} \mathrm{~N}\right]$ & $2.69 \pm 0.14$ & $-1228 \pm 45$ & $-228 \pm 77$ & $9139 \pm 3499$ & $33 \pm 12$ \\
\hline$\left[\mathrm{C}_{3} \mathrm{mpyr}\right]\left[\mathrm{Tf}_{2} \mathrm{~N}\right]$ & $2.69 \pm 0.15$ & $-1236 \pm 45$ & & & \\
\hline$\left[\mathrm{C}_{4} \mathrm{mpyr}\right]\left[\mathrm{Tf}_{2} \mathrm{~N}\right]$ & $2.75 \pm 0.11$ & $-1281 \pm 33$ & & & \\
\hline$\left[\mathrm{C}_{3}\right.$ mpip $]\left[\mathrm{Tf}_{2} \mathrm{~N}\right]$ & $3.05 \pm 0.19$ & $-1366 \pm 56$ & & & \\
\hline
\end{tabular}

${ }^{a}$ Standard deviation.

TABLE 4: Standard Thermodynamic Molar Properties of Solution of ILs in Water at 298.15 K

\begin{tabular}{lrcr}
\hline \multicolumn{1}{c}{$\mathrm{IL}$} & $\begin{array}{c}\left(\Delta_{\mathrm{sol}} H_{\mathrm{m}}^{0} \pm \sigma^{a}\right) / \\
\mathrm{kJ} \cdot \mathrm{mol}^{-1}\end{array}$ & $\begin{array}{c}\left(\Delta_{\mathrm{sol}} G_{\mathrm{m}}^{0} \pm \sigma^{a}\right) / \\
\mathrm{kJ} \cdot \mathrm{mol}^{-1}\end{array}$ & $\begin{array}{c}\left(\Delta_{\text {sol }} S_{\mathrm{m}}^{0} \pm \sigma^{a}\right) / \\
\mathrm{J} \cdot \mathrm{K}^{-1} \cdot \mathrm{mol}^{-1}\end{array}$ \\
\hline$\left[\mathrm{C}_{4} \mathrm{mim}\right]\left[\mathrm{PF}_{6}\right]$ & $12.6 \pm 1.5$ & $16.66 \pm 0.01$ & $-13.5 \pm 5.1$ \\
{$\left[\mathrm{C}_{6} \mathrm{mim}\right]\left[\mathrm{PF}_{6}\right]$} & $12.7 \pm 1.5$ & $19.19 \pm 0.01$ & $-21.5 \pm 5.1$ \\
{$\left[\mathrm{C}_{8} \mathrm{mim}\right]\left[\mathrm{PF}_{6}\right]$} & $12.6 \pm 1.5$ & $22.24 \pm 0.05$ & $-32.2 \pm 5.2$ \\
{$\left[\mathrm{C}_{4} \mathrm{C}_{1} \mathrm{mim}\right]\left[\mathrm{PF} \mathrm{PF}_{6}\right]$} & $11.9 \pm 1.5$ & $17.63 \pm 0.01$ & $-19.2 \pm 5.1$ \\
{$\left[\mathrm{C}_{4} \mathrm{mim}\right]\left[\mathrm{Tf}_{2} \mathrm{~N}\right]^{35}$} & $7.1 \pm 1.5$ & $20.05 \pm 0.01$ & $-43.4 \pm 5.1$ \\
{$\left[\mathrm{C}_{4} \mathrm{mim}\right]\left[\mathrm{C}(\mathrm{CN})_{3}\right]$} & $10.1 \pm 1.5$ & $12.59 \pm 0.01$ & $-8.5 \pm 5.1$ \\
{$\left[\mathrm{C}_{3} \mathrm{mpy}\right]\left[\mathrm{Tf}_{2} \mathrm{~N}\right]$} & $6.5 \pm 1.5$ & $19.56 \pm 0.02$ & $-43.9 \pm 5.1$
\end{tabular}

${ }^{a}$ Standard deviation.

tions are presented in Table 3. The proposed correlations showed a relative maximum deviation from the experimental mole fraction data of $4 \%$.

The very low solubility of the studied ILs in water enables the use of eqs $1-3$ to calculate the associated thermodynamic molar functions of solution at $298.15 \mathrm{~K}$. The standard molar enthalpy, Gibbs energy, and entropy of solution are reported in Table 4.

The enthalpies of solution of the ILs in water at $298.15 \mathrm{~K}$ show that this is an endothermic process, which is independent of the alkyl chain length and of the alkyl substitution number. Just small differences in the enthalpies of solution are observed for both the cation family and the anion identity. These observations are in agreement with those obtained for the enthalpy of dissolution of $n$-alkanes in water at $298.15 \mathrm{~K}$, which also display almost no dependence on the linear chain carbon number. ${ }^{57}$ However, the ionic liquids, as the $n$-alkanes and other organic compounds that are poorly soluble in water, present a slight increase in their solubility in water with the temperature at temperatures close to and above to room temperature. The inspection of Table 4, where the results previously obtained for the $\left[\mathrm{C}_{4} \operatorname{mim}\right]\left[\mathrm{Tf}_{2} \mathrm{~N}\right]^{35}$ were included, indicates that the enthalpies of solution seem to be defined primarily by the anion identity, which is in agreement with the discussion above about the solvation of the anion being the main feature behind the ionic liquid solubility with water.

The experimental entropies of solution of ILs in water display a small decrease in the entropic effect of approximately -5 $\mathrm{J} \cdot \mathrm{K}^{-1} \cdot \mathrm{mol}^{-1}$ per methylene addition to the $\left[\mathrm{C}_{n} \mathrm{mim}\right]\left[\mathrm{PF}_{6}\right]$ cation, corroborating the results found previously for the $\left[\mathrm{C}_{n} \operatorname{mim}\right]\left[\mathrm{Tf}_{2} \mathrm{~N}\right]$ series. ${ }^{35}$ Therefore, it can be concluded that the decrease of the ILs solubility with the increase of the alkyl side chain is driven by the decrease in the entropy of dissolution. The same behavior is also observed for the $n$-alkanes $\left(\mathrm{C}_{n} \mathrm{H}_{n+2}\right.$, with $\left.n=5-9\right)$ dissolution in water, where the enthalpies of solution are also almost independent of the alkyl chain length and a remarkable entropic effect of approximately $-30 \mathrm{~J} \cdot \mathrm{K}^{-1} \cdot \mathrm{mol}^{-1}$ per methylene addition is observed. ${ }^{57,58}$ As for the $\left[\mathrm{C}_{4} \mathrm{mim}\right]\left[\mathrm{C}(\mathrm{CN})_{3}\right]$ and $\left[\mathrm{C}_{3} \mathrm{mpy}\right]\left[\mathrm{Tf}_{2} \mathrm{~N}\right]$ ILs, there is an increase and decrease, respectively, in the entropic effect, which are associated with the high hydrophilicity of the anion and hydrophobicity of the cation. 
Furthermore, the molar entropies of solution suggest that the ILs dissolution in water is controlled by the anion solvation in the IL-rich phase. The lower the entropic change, the higher the solubility of the ILs in water, as can be seen by comparing the solubilities for $\left[\mathrm{C}_{4} \mathrm{mim}\right]\left[\mathrm{Tf}_{2} \mathrm{~N}\right],\left[\mathrm{C}_{4} \mathrm{mim}\right]\left[\mathrm{PF}_{6}\right]$ and $\left[\mathrm{C}_{4} \mathrm{mim}\right]-$ $\left[\mathrm{C}(\mathrm{CN})_{3}\right]$. This can be explained by the fact that the $\left[\mathrm{C}_{4} \mathrm{mim}\right]-$ $\left[\mathrm{C}(\mathrm{CN})_{3}\right]$ is an highly solvated IL in the IL-rich phase, leading to a small entropic change when it goes to the water-rich phase. The same analogy can be established for the $\left[\mathrm{C}_{4} \mathrm{mim}\right]\left[\mathrm{Tf}_{2} \mathrm{~N}\right]$ that is a more hydrophobic IL and suffers a larger entropic change when it partitions to the water-rich phase.

Liquid-Liquid Equilibrium Prediction using COSMORS. Common approaches for correlating or predicting fluid mixture properties, such as EoS and GCMs methods, require a large experimental data collection prior to their application. On top of that, the huge number of possible combinations available for ILs makes their use extremely exhaustive. The current major requirement in the field of ILs is a predictive method that could scan the ILs possible combinations and their mixtures, prior to making extensive experimental measurements.

COSMO-RS is a unique method for predicting the thermodynamic properties of mixtures on the basis of unimolecular quantum chemical calculations for individual molecules. ${ }^{37-41}$ COSMO-RS merges together the electrostatic advantages and the computational efficiency of the quantum chemical dielectric continuum solvation model COSMO with a statistical thermodynamics approach. The standard procedure of COSMO-RS calculations can be divided into two primordial stages: quantum chemical COSMO calculations for the molecular species involved and COSMO-RS statistical calculations performed within the COSMOtherm program. ${ }^{37-41,59,60}$

Within the COSMO calculations, all of the molecules are supposed as solute molecules in a virtual conductor environment, where a polarization charge density on the interface between the molecule and the conductor is induced. These charges act back on the solute and generate a more polarized electron density than in vacuum. During the quantum chemical self-consistency cycle, the solute molecule is converged to its energetically optimal state in a conductor with respect to electron density and the molecular geometry can be optimized using conventional methods for calculations in vacuum. ${ }^{37-41}$

The COSMO-RS calculation procedure is performed using the COSMOtherm program, ${ }^{59,60}$ where all of the interactions between molecules are described as contact interactions of the molecular surfaces, correlating them to the screening charge densities of the interacting surface pieces. For the statistical mechanical calculations, the molecular surface is split into small effective areas and contact with each of these areas is considered to be independent. Finally, the chemical potential of each component is calculated using statistical thermodynamics and from these liquid-liquid equilibria (LLE), vapor-liquid equilibria (VLE) and other properties of the mixture can be derived.

Within the COSMOtherm program, a pseudobinary approach was used to calculate the LLE of the ILs and water systems, with the IL cation and anion introduced as separated compounds with the same mole fraction. The chemical potentials are calculated for the ternary system (anion + cation + water), where the chemical potential of the IL is the sum of the chemical potentials of both the cation and anion. ${ }^{42,48}$ All of the COSMORS calculations were done at the BP/TZVP level (Turbomole, ${ }^{61,62} \mathrm{DFT} / \mathrm{COSMO}$ calculation with the BP functional and $\mathrm{TZVP}^{63}$ basis set using the optimized geometries at the same level of theory) and at the parameter file BP_TZVP_C21_0105 with the derived ions lowest energy conformers. The comparison

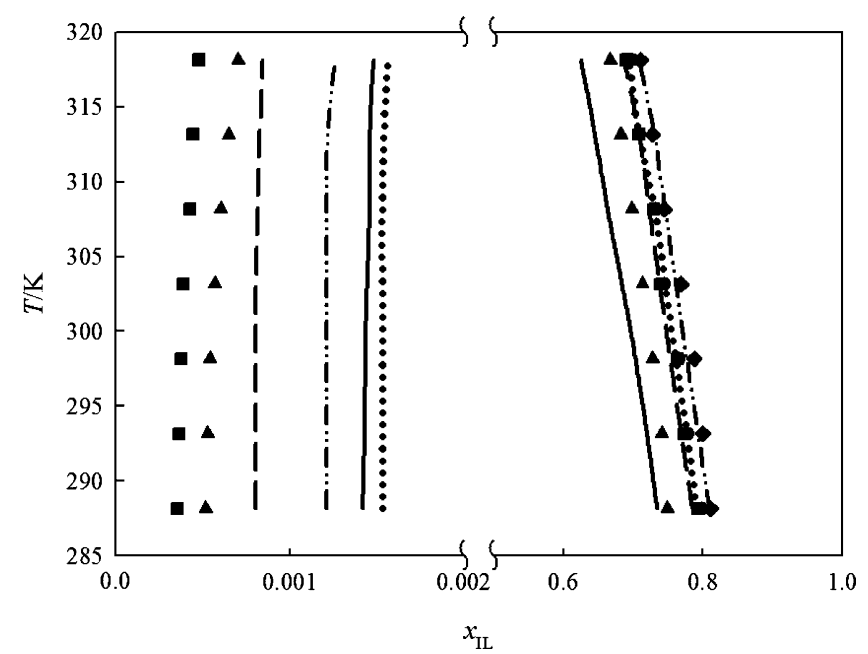

Figure 2. Liquid-liquid phase diagram for water and ILs: $(\mathbf{\Lambda})(-)$, $\left[\mathrm{C}_{3} \operatorname{mim}\right]\left[\mathrm{Tf}_{2} \mathrm{~N}\right] ;{ }^{35}(\mathbf{\square})(--),\left[\mathrm{C}_{3} \mathrm{mpy}\right]\left[\mathrm{Tf}_{2} \mathrm{~N}\right] ;(\bullet)(\bullet \bullet \bullet),\left[\mathrm{C}_{3} \mathrm{mpyr}\right]-$ $\left[\mathrm{Tf}_{2} \mathrm{~N}\right],(\bullet)(\bullet-\bullet \bullet),\left[\mathrm{C}_{3} \mathrm{mpip}\right]\left[\mathrm{Tf}_{2} \mathrm{~N}\right]$. The single symbols and the solid lines represent, respectively, the experimental data and COSMO-RS predictions.

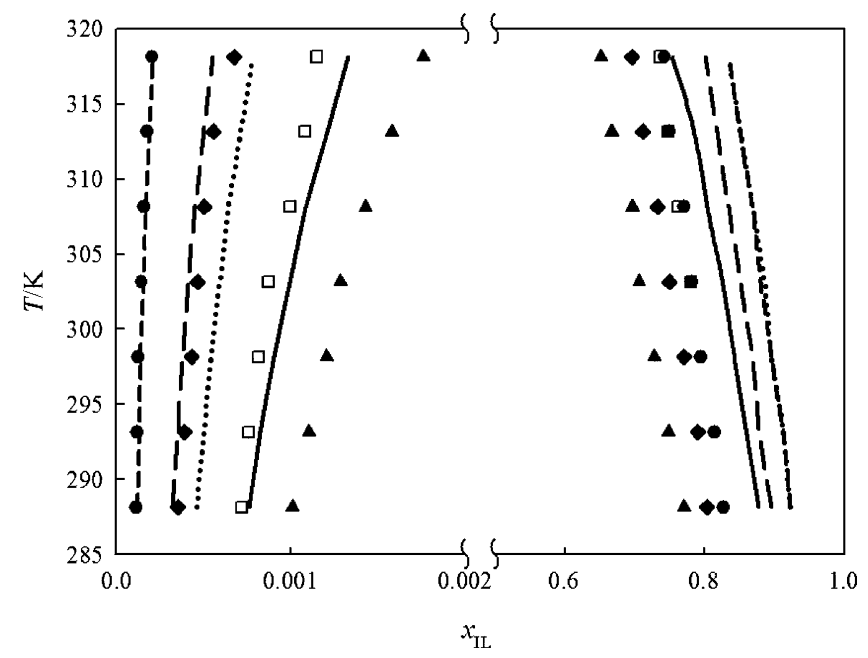

Figure 3. Liquid-liquid phase diagram for water and ILs: $(\mathbf{\Lambda})(-)$, $\left[\mathrm{C}_{4} \mathrm{mim}\right]\left[\mathrm{PF}_{6}\right] ;(\diamond)(--),\left[\mathrm{C}_{6} \mathrm{mim}\right]\left[\mathrm{PF}_{6}\right] ;(\bullet)(---),\left[\mathrm{C}_{8} \mathrm{mim}\right]\left[\mathrm{PF}_{6}\right]$; (口) (०००), $\left[\mathrm{C}_{4} \mathrm{C}_{1} \mathrm{mim}\right]\left[\mathrm{PF}_{6}\right]$. The single symbols and the solid lines represent, respectively, the experimental data and COSMO-RS predictions.

between experimental data and the predictive results is presented in Figures 2-5.

The results obtained with COSMO-RS show an acceptable qualitative agreement with the experimental data. Figure 2 presents the cation family influence experimental results and the predictions using COSMO-RS. The same hydrophobic character increase for the IL-rich side with $\left[\mathrm{C}_{3} \mathrm{mim}\right]<\left[\mathrm{C}_{3^{-}}\right.$ mpy $] \leq\left[\mathrm{C}_{3}\right.$ mpyr $]<\left[\mathrm{C}_{3}\right.$ mpip $]$ was found for the experimental data and the predictions, where the comparison with all of the ILs studied is possible. In addition, the similar $\left[\mathrm{C}_{3} \mathrm{mpy}\right]\left[\mathrm{Tf}_{2} \mathrm{~N}\right]$ and $\left[\mathrm{C}_{3} \mathrm{mpyr}\right]\left[\mathrm{Tf}_{2} \mathrm{~N}\right]$ solubilities in water are also well predicted by COSMO-RS with no large deviations between both ILs. For the water-rich phase, the hydrophobic character increase of the experimental results $\left[\mathrm{C}_{3} \mathrm{mim}\right]<\left[\mathrm{C}_{3} \mathrm{mpy}\right]$ is also well predicted.

Figures 3 and 4 present the alkyl chain length influence, while maintaining the anion, for two different cation families, imidazolium- and pyrrolidinium-based ILs. For both cation families, the same trend was observed with a qualitative good prediction of the cation hydrophobicity increase with the alkyl chain length. Furthermore, COSMO-RS correctly describes the different 


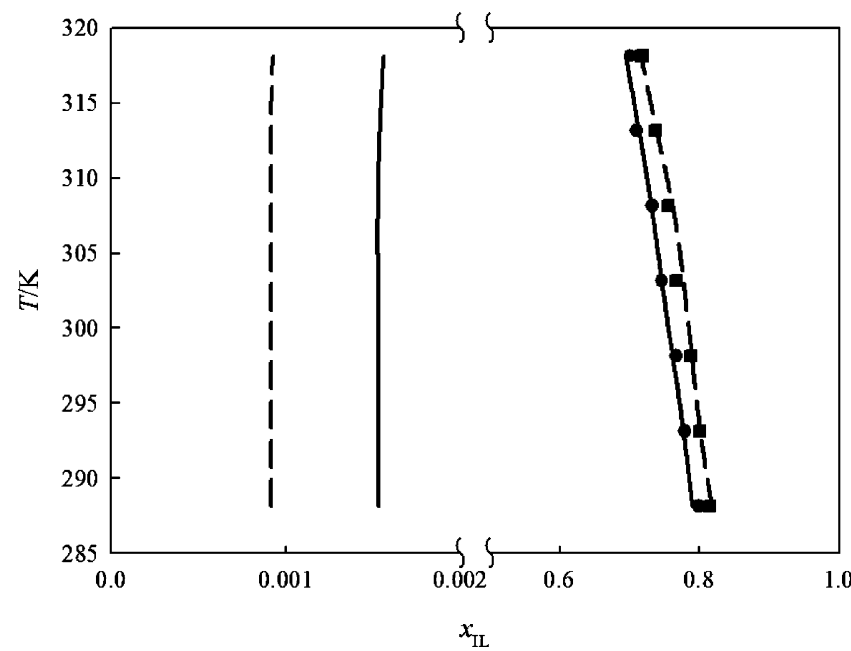

Figure 4. Liquid-liquid phase diagram for water and ILs: $(\bullet)(-)$, $\left[\mathrm{C}_{3} \mathrm{mpyr}\right]\left[\mathrm{Tf}_{2} \mathrm{~N}\right] ;(\boldsymbol{\square})(--),\left[\mathrm{C}_{4} \mathrm{mpyr}\right]\left[\mathrm{Tf}_{2} \mathrm{~N}\right]$. The single symbols and the solid lines represent, respectively, the experimental data and COSMO-RS predictions.

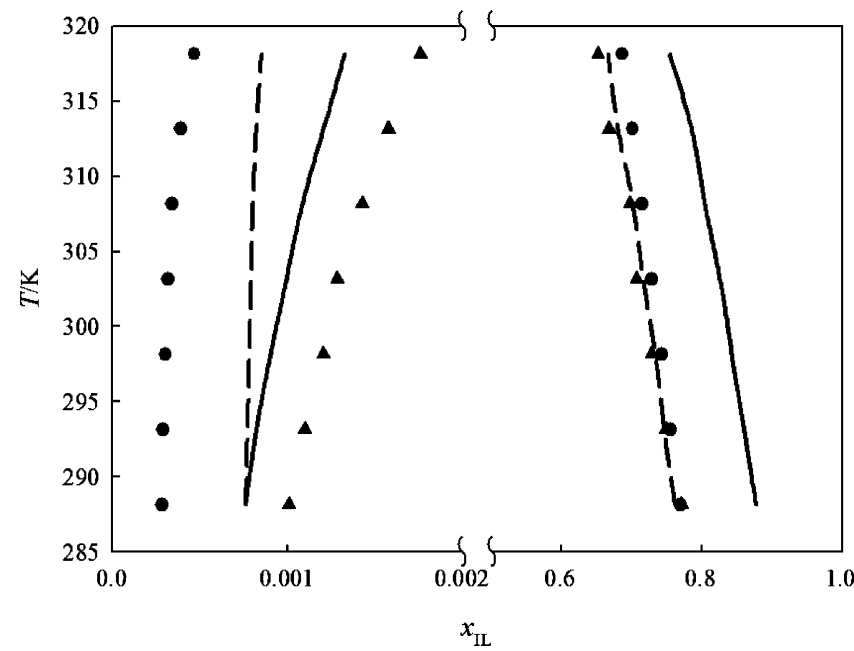

Figure 5. Liquid-liquid phase diagram for water and ILs: $(\boldsymbol{\Delta})(-)$, $\left[\mathrm{C}_{4} \mathrm{mim}\right]\left[\mathrm{PF}_{6}\right] ;(\bullet)(--),\left[\mathrm{C}_{4} \mathrm{mim}\right]\left[\mathrm{Tf}_{2} \mathrm{~N}\right] .{ }^{35}$ The single symbols and the solid lines represent, respectively, the experimental data and COSMO-RS predictions.

behavior of the inclusion of the third methyl substitution in $\left[\mathrm{C}_{4} \mathrm{C}_{1} \mathrm{mim}\right]\left[\mathrm{PF}_{6}\right]$ in both phases, proving to be able to correctly predict the hydrophobic tendency in both the aqueous and ILrich phases. Although, it should be noted that besides the qualitative trend good predictions the quantitative predictions reasonably deviate from the experimental results.

For the anion influence presented in Figure 5, some deviations from experimental data were found. COSMO-RS incorrectly predicted a complete miscibility between $\left[\mathrm{C}_{4} \mathrm{mim}\right]\left[\mathrm{C}(\mathrm{CN})_{3}\right]$ and water in the temperature range studied experimentally. It also fails in the IL-rich phase prediction for the $\left[\mathrm{C}_{4} \mathrm{mim}\right]\left[\mathrm{PF}_{6}\right]$ and $\left[\mathrm{C}_{4} \mathrm{mim}\right]\left[\mathrm{Tf}_{2} \mathrm{~N}\right]$ direct comparison because it predicts a higher solubility of water in $\left[\mathrm{C}_{4} \mathrm{mim}\right]\left[\mathrm{Tf}_{2} \mathrm{~N}\right]$ than in $\left[\mathrm{C}_{4} \mathrm{mim}\right]\left[\mathrm{PF}_{6}\right] . \mathrm{A}$ possible explanation is the fact that $\left[\mathrm{Tf}_{2} \mathrm{~N}\right]$ is a stronger Lewis base than $\left[\mathrm{PF}_{6}\right]$ and, conversely, $\left[\mathrm{PF}_{6}\right]$ has a greater charge density than $\left[\mathrm{Tf}_{2} \mathrm{~N}\right]$, thus allowing stronger Coulombic interactions.

In spite of the quantitative deviations obtained with COSMORS from experimental data, it showed to be an useful predictive method for the a priori scanning of the large number of ILs in order to find suitable candidates, or to help in the design of new ILs, before extensive experimental measurements. How- ever, some limitations were found in the anion influence prediction for the mutual solubilities with water.

\section{Conclusions}

New and original data for mutual solubilities between water and hydrophobic imidazolium-, pyridinium-, pyrrolidinium-, and piperidinium-based cations in combination with bis(trifluoromethylsulfonyl)imide-, hexafluorophosphate-, and tricyanomethanebased anions in the temperature range between 288.15 and $318.15 \mathrm{~K}$ and at atmospheric pressure were presented. The hydrophobic tendency of the cation family increases from imidazolium- to pyridinium- to pyrrolidinium- to piperidiniumbased ILs and with the alkyl chain length increase within the same cation family. Furthermore, the inclusion of a third methyl group replacing the most acidic hydrogen of the imidazolium cation showed to have different impacts in both rich phases, which was addressed by the relative influence of the hydrogenbonding capacity in both phases. The anion hydrophobic tendency increases from tricyanomethane- to hexafluorophosphate- to bis(trifluoromethylsulfonyl)imide-based anions ILs. Moreover, the discussed amphiphilic character of the studied salts can be used to fine tune the ILs mutual solubilities with water and to manage their ecotoxicity impact.

From the ILs in water solubility temperature dependence, the standard molar thermodynamic functions of solution at infinite dilution were determined. The molar enthalpies of solution of the ILs in water at $298.15 \mathrm{~K}$ showed to be essentially independent of the alkyl chain length in the temperature range studied. The decrease of the ILs solubility in water with the alkyl chain length increase is driven by the decrease of the entropy of dissolution. The behavior of ILs in water is qualitatively very similar to that observed for the $n$-alkanes and other organic compounds poorly soluble in water. Also, the increase of the ILs solubility in water due to the anion seems to be controlled mainly by their entropic variation that reflects their solvation in the IL-rich phase.

COSMO-RS showed to be an a priori method of selection for the IL-water binary systems phase behavior qualitative prediction, which may be of considerable value for the design of suitable ILs for practical applications and with expected mutual solubilities.

Acknowledgment. We are thankful for financial support from Fundação para a Ciência e a Tecnologia (Project POCI/ EQU/58152/2004) and Ph.D. grant (SFRH/BD/14134/2003) of Mara G. Freire and postdoctoral grant (SFRH/BPD/23246/2005) of Ramesh L. Gardas. We also acknowledge F. Eckert and A. Klamt, COSMOtherm, Version C2.1, Release 01.05, COSMOlogic GmbH \& Co. KG, Leverkusen, Germany, 2005, and M. Diedenhofen of COSMOlogic for advice and assistance in the use of COSMOtherm.

\section{References and Notes}

(1) Welton, T. Chem. Rev. 1999, 99, 2071.

(2) Rogers, R. D.; Seddon, K. R. Science 2003, 302, 792.

(3) Earle, M. J.; Esperanca, J. M. S. S.; Gilea, M. A.; Lopes, J. N. C.; Rebelo, L. P. N.; Magee, J. W.; Seddon, K. R.; Widegren, J. A. Nature 2006, $439,831$.

(4) Zhao, H. Chem. Eng. Commun. 2006, 193, 1660.

(5) Huddleston, J. G.; Willauer, H. D.; Swatloski, R. P.; Visser, A. E.; Rogers, R. D. Chem. Commun. 1998, 16, 1765.

(6) Fadeev, A. G.; Meagher, M. M. Chem. Commun. 2001, 295.

(7) McFarlane, J.; Ridenour, W. B.; Luo, H.; Hunt, R. D.; DePaoli, D. W.; Ren, R. X. Sep. Sci. Technol. 2005, 40, 1245-1265.

(8) Papaiconomou, N.; Salminen, J.; Prausnitz, J. M. Book of Abstracts, 16th Symposium on Thermophysical Properties; Boulder, CO, 2006; p 55.

(9) Zhao, D.; Liao, Y.; Zhang, Z. Clean 2007, 35, 42. 
(10) Ranke, J.; Müller, A.; Bottin-Weber, U.; Stock, F.; Stolte, S.; Arning, J.; Störmann, R.; Jastorff, B. Ecotoxicol. Environ. Saf. 2007, 67, 430.

(11) Docherty, K. M.; Kulpa, C. F. Green Chem. 2005, 7, 185.

(12) Couling, D. J.; Bernot, R. J.; Docherty, K. M.; Dixon, J. K.; Maggin, E. J. Green Chem. 2006, $8,82$.

(13) Garcia, M. T.; Gathergoof, N.; Scammells, P. J. Green Chem. 2005 7,9

(14) Seddon, K. R.; Stark, A.; Torres, M.-J. Pure Appl. Chem. 2000, $72,2275$.

(15) Freire, M. G.; Carvalho, P. J.; Fernandes, A. M.; Marrucho, I. M.; Queimada, A. J.; Coutinho, J: A. P. J. Colloid Interface Sci. 2007, 314 621.

(16) Gardas, R. L.; Freire, M. G.; Carvalho, P. J.; Marrucho, I. M.; Fonseca, I. M: A.; Ferreira, A. G. M.; Coutinho, J. A. P. J. Chem. Eng. Data 2007, 52, 80 .

(17) Huddleston, J. G.; Visser, A. E.; Reichert, W. M.; Willauer, H. D.; Broker, G. A.; Rogers, R. D. Green Chem. 2001, 3, 156.

(18) Najdanovic-Visak, V.; Rebelo, L. P. N.; Ponte, M. N. Green Chem. 2005, 7, 443 .

(19) Ventura, S. P. M.; Pauly, J.; Daridon, J. L.; Lopes da Silva, J. A.; Marrucho, I. M.; Dias, A. M. A.; Coutinho, J. A. P. Green Chem. 2007, submitted.

(20) Fu, D. B.; Sun, X. W.; Pu, J. J.; Zhao, S. Q. J. Chem. Eng. Data 2006, 51,371 10873

(22) Anthony, J. L.; Maginn, E. J.; Brennecke, J. F. J. Phys. Chem. B 2001, 105, 10942 .

(23) Wong, D. S. H.; Chen, J. P.; Chang, J. M.; Chou, C. H. Fluid Phase Equilib. 2002, 194-197, 1089.

(24) Crosthwaite, J. M.; Aki, S. N. V. K; Maginn, E. J.; Brennecke, J. F. J. Phys. Chem. B 2004, 108, 5113.

(25) Rebelo, L. P. N.; Najdanovic-Visak, V.; Visak, Z. P.; Ponte, M. N.; Szydlowski, J.; Cerdeirina, C. A.; Troncoso, J.; Romani, L.; Esperança, J. M. S. S.; Guedes, H. J. R.; Sousa, H. C. Green Chem. 2004, 6, 369.

(26) Najdanovic-Visak, V.; Esperança, J. M. S. S.; Rebelo, L. P. N.; Ponte, M. N.; Guedes, H. J. R.; Seddon, K. R.; Szydlowski Phys. Chem. Chem. Phys. 2002, 4, 1701

(27) Alfassi, Z. B.; Huie, R. E.; Milman, B. L.; Neta, P. Anal. Bioanal. Chem. 2003, 377, 159.

(28) Shvedene, N. V.; Borovskaya, S. V.; Sviridov, V. V.; Ismailova, E. R.; Pletnev, I. V. Anal. Bioanal. Chem. 2005, 381, 427.

(29) Domańska, U.; Marciniak, A. Green Chem. 2007, 9, 262.

(30) Domańska, U.; Bakala, I.; Pernak, J. J. Chem. Eng. Data 2007, 52,309 .

(31) Bonhôte, P.; Dias, A. P.; Papageorgiou, N.; Kalyanasundaram, K.; Gratzel, M. Inorg. Chem. 1996, 35, 1168.

(32) Toh, S. L. I.; McFarlane, J.; Tsouris, C.; DePaoli, D. W.; Luo, H.; Dai, S. Solvent Extr. Ion Exch. 2006, 24, 33.

(33) Papaiconomou, N.; Yakelis, N.; Salminen, J.; Bergman, R.; Prausnitz, J. M. J. Chem. Eng. Data 2006, 51, 1389.

(34) Papaiconomou, N.; Salminen, J.; Lee, J. M.; Prausnitz, J. M. J. Chem. Eng. Data 2007, 52, 833.

(35) Freire, M. G.; Carvalho, P. J.; Gardas, R. L.; Marrucho, I. M.; Santos, L. M. N. B. F.; Coutinho, J. A. P. J. Phys. Chem. B, submitted for publication.
(36) Freire, M. G.; Santos, L. M. N. B. F.; Fernandes, A. M.; Coutinho, J. A. P.; Marrucho, I. M. Fluid Phase Equilib., in press, DOI:10.1016/ j.fluid.2007.07.033

(37) Klamt, A.; Schuurmann, G. J. Chem. Soc., Perkin Trans. 2 1993, 2, 799.

(38) Klamt, A. J. Phys. Chem. 2005, 99, 2224.

(39) Klamt, A.; Eckert, F. Fluid Phase Equilib. 2000, 172, 43.

(40) Klamt, A. COSMO-RS from Quantum Chemistry to Fluid Phase

Thermodynamics and Drug Design; Elsevier: Amsterdam, 2005.

(41) Eckert, F.; Klamt, A. AIChE J. 2002, 48, 369.

(42) Freire, M. G.; Santos, L. M. N. B. F.; Marrucho, I. M.; Coutinho,

J. A. P. Fluid Phase Equilib. 2007, 255, 167.

(43) Marsh, K. N.; Deev, A. V.; Wu, A. C. -T.; Tran, E.; Klamt, A. Korean J. Chem. Eng. 2002, 19, 357.

(44) Domańska, U.; Pobudkowska, A.; Eckert, F. Green Chem. 2006, $8,268$.

(45) Domańska, U.; Pobudkowska, A.; Eckert, F. J. Chem. Thermodyn. 2006, 38, 685 .

(46) Sahandzhieva, K.; Tuma, D.; Breyer, S.; Kamps, A. P.-S.; Maurer, G. J. Chem. Eng. Data 2006, 51, 1516.

(47) Wu, C.-T.; Marsh, K. N.; Deev, A. V.; Boxall, J. A. J. Chem. Eng. Data 2003, 48, 486.

(48) Freire, M. G.; Ventura, S. P. M.; Santos, L. M. N. B. F.; Marrucho,

I. M.; Coutinho, J. A. P. Braz. J. Chem. Eng., in press.

(49) Swatloski, R. P.; Holbrey, J. D.; Rogers, R. D. Green Chem. 2003, 5,361 .

(50) Adkins, C. J. Equilibrium Thermodynamics; McGraw Hill: London, England, 1968.

(51) Fernández-Galán, R.; Manzano, B. R.; Otero, A.; Lanfranchi, M.;

Pellinghelli, M. A. Inorg. Chem. 1994, 33, 2309.

(52) Lu, Y.; King, F. L.; Duckworth, D. C. J. Am. Soc. Mass Spectrom. 2006, 17, 939.

(53) Cooks, R. G.; Koskinen, J. T.; Thomas, P. D. Int. J. Mass Spectrom. 1999, 34,85 .

(54) Gardas, R. L.; Freire, M. G.; Carvalho, P. J.; Marrucho, I. M.; Fonseca, I. M. A.; Ferreira, A. G. M.; Coutinho, J. A. P. J. Chem. Eng. Data 2007, 52, 1881

(55) Crosthwaite, J. M. Muldoon, M. J.; Aki, S. N. V. K.; Maginn, E. J.; Brennecke, J. F. J. Phys. Chem. B 2006, 110, 9354.

(56) Crosthwaite, J. M.; Aki, S. N. V. K.; Maginn, E. J.; Brennecke, J.

F. Fluid Phase Equilib. 2005, 228-229, 303.

(57) Tsonopoulos, C. Fluid Phase Equilib. 1999, 156, 21.

(58) Afeefy, H. Y.; Liebman, J. F.; Stein, S. E. "Neutral Thermochemical Data" in NIST Chemistry WebBook, NIST Standard Reference Database Number 69; Linstrom, P. J., Mallard, W. G., Eds.; National Institute of Standards and Technology: Gaithersburg, MD, June 2005 (http://webbook.nist.gov).

(59) Eckert, F. COSMOtherm User's Manual, version C2.1, Release 01.05; COSMOlogic GmbH \& Co. Kg: Leverkusen, Germany, 2005.

(60) Eckert, F.; Klamt, A. COSMOtherm, version C2.1, Release 01.05, COSMOlogic GmbH \& Co. Kg: Leverkusen, Germany, 2005.

(61) Schäfer, A.; Klamt, A.; Sattel, D.; Lohrenz, J. C. W.; Eckert, F. Phys. Chem. Chem. Phys. 2000, 2, 2187.

(62) Ahlrichs, R.; Bär, M.; Häser, M.; Horn, H.; Kölmel, C. Chem. Phys. Letters 1989, 162, 165 .

(63) Schäfer, A.; Huber, C.; Ahlrichs, R. J. Chem. Phys. 1994, 100, 5829 